\title{
Expert, intelectual e/ou polímata? Uma contribuição para a História da Educação Matemática
}

\section{Expert, intellectual and/or polymathic? A contribution to the History of Mathematical Education}

\author{
Oscar Silva Neto \\ Orcid: https://orcid.org/0000-0001-8368-8119 \\ Programa de Pós-Graduação em Educação Científica e Tecnológica, Universidade \\ Federal de Santa Catarina/Instituto Federal de Santa Catarina, Florianópolis, \\ Brasil, oscar.neto@ifsc.edu.br \\ David Antonio da Costa \\ Orcid: https://orcid.org/0000-0003-4493-9207 \\ Programa de Pós-Graduação em Educação Científica e Tecnológica, Universidade \\ Federal de Santa Catarina, Florianópolis, Brasil, david.costa@ufsc.br
}

Received on 30/11/2020 - Approved on 02/12/2020

\begin{abstract}
Resumo
O presente trabalho foi realizado com apoio da Coordenação de Aperfeiçoamento de Pessoal de Nível Superior - Brasil (Capes) - Código de Financiamento 001 e surgiu do desdobramento de uma pesquisa de doutorado em andamento que tem o objetivo de problematizar os conceitos de expert, intelectual e polímata, no intuito de auxiliar as pesquisas no âmbito da História da Educação Matemática. Foram utilizados referenciais teórico-metodológicos como Hofstetter e Schneuwly (2017), para definir experts; Vieira (2011), para definir intelectuais; e Burke $(2011 ; 2016)$ para definir polímatas. Os estudos mostram que cada vocábulo possui uma definição própria, com características que lhes são peculiares e que não são tratados como sinônimos, tampouco como antônimos. Eles simplesmente possuem funções diferentes e o que importa, na realidade, é perceber o conhecimento que produzem.
\end{abstract}

Palavras-chave: Experts. Intelectuais. Polímatas. 


\begin{abstract}
This study was financed in part by the Coordenação de Aperfeiçoamento de Pessoal de Nível Superior - Brasil (Capes) - Finance Code 001 and arose from the unfolding of an ongoing doctoral research that aims to problematize the concepts of expert, intellectual and polymath, in order to assist research in the context of the History of Mathematics Education. Theoretical and methodological references were used, such as Hofstetter and Schneuwly (2017), to define experts; Vieira (2011), to define intellectuals; and Burke $(2011 ; 2016)$ to define polymaths. Studies show that each word has its own definition, with characteristics that are peculiar to them and that are not treated as synonyms, nor as antonyms. They simply have different functions and what really matters is to perceive the knowledge they produce.
\end{abstract}

Keywords: Experts. Intellectuals. Polymaths.

"O uso da mesma palavra em muitas línguas não é fruto do acaso, mas o sintoma de uma realidade à qual é preciso atentar."

(Hofstetter \& Schneuwly, 2017, p. 47)

L'usage du même mot dans plusieurs langues n'est pas le fruit du hasard, mais le symptôme d'une réalité à laquelle il rend attentif. (Hofstetter \& Schneuwly, 2014, p. 41)

\title{
O sintoma de uma realidade
}

No início deste artigo, a epígrafe traz um excerto da obra de Hofstetter e Schneuwly (2014), traduzido para o português em 2017, no qual se percebe que a utilização de uma mesma palavra em diversas línguas é um fato que merece atenção, que salta aos olhos de pesquisadores, inclusive os da área da história e, por que não, os da história da educação.

Uma análise desses vocábulos traz à tona sua historicidade, sua constituição, seus usos e desusos em diversas partes do globo. Cada sociedade, a seu tempo e a seu modo, se apropria e aplica determinada palavra em seu próprio contexto sócio-político-econômico. Para que não se cometa um anacronismo, pesquisadores da história se debruçam sobre seus possíveis significados, respeitando o momento de sua inserção no cotidiano e percebendo quais alterações sofreram (ou não) ao longo dos tempos.

Este texto tem a intenção de problematizar o uso das palavras expert, intelectual e polímata, categorias de análise que vêm sendo utilizadas nas pesquisas do Grupo Associado de Estudos e Pesquisas sobre História da Educação Matemática $^{1}$ (GHEMAT-Brasil) e que tem possibilitado a difusão de saberes relacionados ao ensino e à formação de professores no Brasil. O que se quer é trazer para o debate educacional essas questões e auxiliar nas pesquisas na identificação destes saberes, com enfoque para os relacionados à Matemática, principalmente à matemática escolar. 
Como nenhuma escrita é neutra, este trabalho teve como ponto de partida o artigo de Morais (2019) que analisou os termos expert, expertise e intelectual, na tentativa de situar o que vem sendo considerado pelo GHEMAT-Brasil como "experts em educação", colocando em contraste o termo intelectual, também largamente utilizado nas pesquisas em História da Educação.

A novidade, porém, é acrescentar ao debate o termo "polímata", recentemente inserido nas leituras do mesmo Grupo, a partir das leituras de Burke (2016) e sua história do conhecimento.

A partir destas considerações, o trabalho será constituído de três partes (uma para cada vocábulo) e uma ao final, destinada a atentar para aquele "sintoma de uma realidade" proposto pelos autores nos escritos iniciais.

\section{O primeiro sintoma: os experts}

É bem verdade que o vocábulo expertjá é de muito visto e ouvido falar. Como exemplo disto, Morais (2018) ilustra o encontro que teve com um livro datado do ano de 1835 cujo título era: Des experts et code du proprietaire-foncier ${ }^{2}$. Curiosamente, há realmente que se questionar o que significava o termo naquele ano, na região da Argélia.

O tema também está presente nas pesquisas articuladas à investigação do saber profissional do professor que ensina matemática, realizadas pelo GHEMATBrasil.

Junto a esse projeto, outra pesquisa articulada à investigação do saber profissional, voltará a atenção para os professores como experts, analisando ao longo de cem anos, como ocorreram as mudanças no saber profissional do professor que ensina matemática: "Os experts e sistematização da matemática para o ensino e para a formação de professores, 1890-1990", com o apoio do CNPq, projeto Edital Universal Faixa C, com duração de três anos para a sua realização (Valente, 2020, p. 604).

Consultando o Dictionnaire Universel, contenant generalement tous les mots françois, tant vieux que modernes, e les termes des sciences et des arts, encontrase a seguinte definição:

EXPERT, adj. Qui est habile en son art. Le Marechal expert. Ce Chirurgien est fort expert en son art.

EXPERT est quelquefois substantif, \& signifie un homme habile \& connoissans en quelque chose, qu'on nomme pour la visiter \& en faire le rapport. Les reparations feront visitées par Experts \& gens à ce connoissant. On paye les fruits du rachat d'un relief au dire des Experts. II faut deux Experts pour la validité d'um rapport :si l'une des parties refuse de convenir d'un Expert, le juge de nomme d'office. Par arrêt du Conseil en 1690, le Roi a crée un certain nombre d'Experts jurez pour chaque ville du Royaume, \& pour celle de Paris : c'est à-dire. Architectes, \& Entrepreneurs, Maçons, \& Charpentiers, qui feuls pouvent être nommez d'office pour être arbitres des contestations entre les Bourgeois. Ces experts dans leurs descentes, \& visites doivent être accompagnez d'un Greffiers des bâtimens, dit de l'Ecritoire, pour écrire la minute de leur rapport, \& lors qu'ils ne conviennent pas, on nomme um tiers pour décider la contestation ${ }^{3}$ (Furetière, 1702a, p. 866).

Como se pode perceber, muitas vezes a palavra é tida como sinônimo de especialista ou de uma pessoa muito inteligente. Em resumo, Morais (2018) identifica que o expert é o "especialista que detém saberes necessários para 
desempenhar tal função, que tem competência para realizar a tarefa que the foi designada. O que o diferencia é sua expertise profissional" (Morais, 2018, p. 14). E, por conseguinte, define essa expertise como sendo empregada no sentido de "competência do sujeito" (Ibid., p. 17).

Morais (2018) ainda destaca que estes dois verbetes não são usuais na literatura brasileira, que tem por costume utilizar as expressões "intelectuais" e "especialistas" no intuito de referir estas últimas como sinônimo das primeiras. Porém, adota-se para este texto a posição de que "o expert também não se confunde com o "intelectual"” ( Ibid., p. 46), categoria que será mais bem detalhada na sequência.

Avança, Morais (2018), no sentido de problematizar o conceito de expert da educação como "vetor de objetivação de saberes no campo profissional, na formação e no ensino" ( Ibid., p. 18). Passa-se, então, a explorar estes conceitos de forma pormenorizada.

Para iniciar este debate, é necessário relacionar o termo expert com uma profissionalização da pedagogia: ela passa de um domínio dos "homens de bem", ou seja, pastores, professores, entre outros, e se disciplinariza ${ }^{4}$ com a ascensão dos acadêmicos e pesquisadores, isto é, dos especialistas, que possuem a função de construir os saberes sobre o sistema escolar, a partir de regras específicas definidas pelo mundo científico (Hofstetter, Schneuwly \& Freymond, 2017, p. 56).

De acordo com os autores, a institucionalização da expertise e do especialista em educação ocorre concomitantemente à entrada em cena do Estado no papel de encarregado da instrução pública como também à emergência do campo disciplinar "ciências da educação". E é ao mesmo tempo que emergem esses experts em educação que "se especializam, se institucionalizam e, nesse movimento, um novo campo de saber é produzido" (Morais, 2018, p. 19).

Surge, portanto, a necessidade de uma definição de expertise. Para os autores, trata-se de

[...] uma instância, em princípio reconhecida como legítima, atribuída a um ou a vários especialistas - supostamente distinguidos pelos seus conhecimentos, atitudes, experiências -, a fim de examinar uma situação, de avaliar um fenômeno, de constatar fatos. Esta expertise é solicitada pelas autoridades do ensino tendo em vista a necessidade de tomar uma decisão (Hofstetter, Schneuwly \& Freymond, 2017, p. 57).

Verifica-se no excerto acima que a expertise é solicitada pelo Estado. Porém, "a expertise é solicitada para uma ajuda essencialmente técnica (Ibid., p. 87). Assim se posiciona Conceição (2019) a respeito deste chamamento do Estado:

De forma contrária, o expert, dentre várias atribuições e características, diferencia-se do intelectual pelo chamamento por parte do Estado a fim de resolver um problema prático devido sua expertise profissional e a resposta a esta demanda (Conceição, 2019, p. 47).

Neste trecho, talvez o leitor já se dê conta de que não são sinônimos os termos expert e intelectual. Porém, deixar-se-á esta análise para o fim do trabalho, na tentativa de costurar os distanciamentos e aproximações entre os termos.

A respeito da convocação por parte do Estado, assim se manifesta a literatura: "uma demanda do Estado implicará na convocação de uma expertise, 
cujos sujeitos são os experts. Essa convocação é disparada pelo reconhecimento da comunidade a que esta instância se filia" (Morais, 2019, p. 10).

Destaque-se que a solicitação desta expertise "participa decisivamente da produção de novos saberes no campo pedagógico" ( Ibid., p. 57). Outras são as falas que sustentam a importância da expertise. Ainda de acordo com os autores suíços,

[...] o fortalecimento e a institucionalização da pesquisa crescente da expertise que acompanha irresistivelmente o desenvolvimento do sistema escolar, dinamiza a produção dos saberes no campo pedagógico de imediato sob a forma heterônoma, ao serviço do Estado (Hofstetter, Schneuwly \& Freymond, 2017, p. 58).

Mais adiante, os autores concluem que: "A expertise é, portanto, realizada por pessoas do meio escolar, isto é, pela profissão docente" (Hofstetter, Schneuwly \& Freymond, 2017, p. 67).

Entretanto, não se pode esquecer que quando se fala da institucionalização da expertise está se falando, em linha de síntese, do especialista em educação (Hofstetter et al., 2013, apud Bertini, Morais \& Valente, 2017, p. 19). Para este trabalho será utilizado o conceito de experts como "personalidades" ou sujeitos da expertise (lbid., p. 18).

Conceição (2019), em sua tese de Doutorado, também conceitua o termo expert. Para ele, é

[...] aquele personagem que possui participação efetiva no ensino e na formação docente deste tempo, como um agente relevante na disseminação e implementação de mudanças educacionais. Ele está diretamente ligado com as políticas públicas e ações do Estado (Conceição, 2019, p. 46).

Acrescente-se a isto também a definição dada por Hofstetter, Schneuwly e Freymond (2017, p. 67): "[...] inspetores, professores do primário e do secundário, diretores de escola. Eles são 'experts' pelo fato de que conhecem perfeitamente o ofício docente e nele se destacam".

A título de exemplo, Tochon (2004) mostra a consideração que se tem com o Inspetor de Educação Nacional, também considerado como um expert, pois

\footnotetext{
Pendant longtemps, et encore actuellement dans certains secteurs, on a considéré que les experts de l'enseignement étaient à l'extérieur de la profession. Par exemple, on énonce que l'inspecteur de l'éducation nationale est un expert du premier degré (1) : par ses activités d'animation pédagogique, il veille à la mise en œuvre de la politique ministérielle. II inspecte les enseignants et évalue leur travail en équipe, participe à leur recrutement et à leur formation. Les personnels de la formation des enseignants bénéficient aussi d'une reconnaissance comme experts ${ }^{5}$ (Faingold, 2001 apud Tochon, 2004, p. 89-90).
}

Além do exemplo citado acima, pode-se mencionar que entre os anos de 1930 a 1970 houve, no Brasil, a emergência de um grupo de especialistas principalmente ligados à escola normal do antigo Distrito Federal e de Belo Horizonte (Villela et al., 2016 apud Bertini, Morais \& Valente, 2017, p. 19).

Ainda na linha dos autores, quando há estabelecimento de consensos e "Quando todos passam a "dizer da mesma coisa", acontece a naturalização do objeto, ou seja, a objetivação. "A produção e a objetivação de saberes é um produto histórico e a expertise participa dele" (lbid., 2017, p. 21). 
Como os experts participam da objetivação destes saberes, importante se deixar registrado que:

Para que esses saberes se tornem um produto coletivo, de fato, busca-se por sua institucionalização. Seguir com a análise histórica desse novo saber [...] é buscar por indícios que dizem do processo de institucionalização desse saber, legitimado por meio de normatizações, disciplinarização, produção de livros didáticos, dentre outros (Bertini, Morais \& Valente, 2017, p. 34).

Como se percebe, os conceitos expert e expertise "carregam consigo problemas de definição por serem ambíguos. Essa condição se dá pelo fato de os próprios atores, na maioria das vezes, não se reconhecem como tal, como experts, como sujeitos da expertise" (Morais, 2019, p. 7).

Mesmo assim sendo, baseado nos autores acima citados, aqui se toma o conceito de expert em educação como sendo: aquele sujeito/personalidade/especialista do meio escolar, distinguido por seus conhecimentos e atitudes, que detém a competência necessária para desempenhar uma tarefa, examinar uma situação e constatar fatos, recrutado pelo Estado, de modo a subsidiar tecnicamente uma decisão e promover a disseminação e implementação de mudanças educacionais, bem como a objetivação e a produção de novos saberes no campo pedagógico, com vistas à sua institucionalização.

Longe de querer ser este trabalho um engessamento do conceito, o que se quer é marcar as considerações a respeito do termo na tentativa de comparações com os próximos a serem apresentados.

\section{O Segundo sintoma: os intelectuais}

Muito se tem discutido, nas pesquisas atuais, sobre a participação e importância dos intelectuais no âmbito da educação. Especificamente, as pesquisas da área da História da Educação têm se debruçado sobre esse tema. A história da educação no Brasil tem uma significativa tradição de estudos acadêmicos sobre o tema dos intelectuais, ainda que os delineamentos e os suportes das análises se tenham alterado ao longo do tempo (Vieira, 2008, p. 65).

Mais ainda, no âmbito do GHEMAT-Brasil, há certas inquietações sobre as proximidades e distâncias dos termos intelectuais versus experts. Para melhor poder realizar este tipo de análise, necessário se faz debruçar sobre os estudos que dizem respeito ao tema, ou seja, investigar através de outras produções bibliográficas o que se tem discutido sobre o "intelectual" para tentar conceituar o que esta pesquisa considera como tal.

O termo intelectual causa polêmica e discussões no âmbito educacional tal qual os experts. Porém, difícil é mensurar a gênese do termo. Estudos mostram que na França e na Itália o termo vem há muito sendo estudado. No Brasil, os intelectuais também ganharam certo destaque nas pesquisas em Educação.

Porém, essa produção a respeito dos intelectuais deve ser tomada com cuidado. Bobbio (1997 apud Vieira, 2015) adverte que: 
reconheçam como partícipes de uma elite cultural, detentora de qualidades e poderes peculiares (Vieira, 2015, p. 6).

Parece que, a partir do trecho acima, o indivíduo deve se reconhecer como tal, como membro de um determinado grupo que possui qualidades e poderes que Ihes são próprios. Em recente publicação, Morais (2019) vai ao encontro do que o autor acima quis dizer. Na tentativa de comparar os conceitos de intelectual e experts, esta última enfatiza que

[...] o conceito "intelectual" deve ser historicizado, considerado como um produto cultural, não naturalizado. É preciso se interrogar do que se fala, sobre o que se fala, e de quando se fala, ou seja, situar historicamente tal conceito (Morais, 2019, p. 6).

No artigo, a autora inicia com uma epígrafe de Clarice Linspector que traz em suas palavras o que considera como intelectual:

Outra coisa que não parece ser entendida pelos outros é quando me chamam de intelectual e eu digo que não sou. De novo, não se trata de modéstia e sim de uma realidade que nem de longe me fere. Ser intelectual é usar sobretudo a inteligência [...]. Ser intelectual é também ter cultura [...]. Literata também não sou porque não tornei o fato de escrever livros "uma profissão", nem uma "carreira". Escrevi-os só quando espontaneamente me vieram, e só quando eu realmente quis [...] (Linspector apud Morais, 2019, p. 3).

A passagem de Linspector mostra que o termo intelectual pode gerar diferentes entendimentos e daí a necessidade de localizá-lo na história e no tempo. Até porque não se sabe ao certo a conotação que o termo detinha em determinado período histórico.

Percebe-se, como se vê na literatura, que o tema foi e ainda é estudado: "Nos anos dois mil os congressos e as publicações da área revelam a continuidade do debate sobre tema dos intelectuais do campo educacional" (Vieira, 2008, p. 66-67).

Vieira (2008) faz um estudo histórico do vocábulo "intelectual". Inicia dizendo que na Grande Polônia, nos anos de 1844, o vocábulo inteligencia foi utilizado "para representar os membros bem educados da sociedade que, apoiados na razão e no conhecimento, assumiriam as responsabilidades de defender os interesses da pátria e do povo" (Veiria, 2008, p. 68).

Já na Rússia, nesse mesmo período, o vocábulo intelligentsia representava a "transliteração da palavra escrita em alfabeto cirílico (интеллигенция) que circulou na literatura desse país na primeira metade do século XIX" (Ibid., p. 68). De acordo com o autor, o vocábulo foi associado à ideia de elite, definida pelo grau de formação e de competência para lidar com a cultura geral e com o conhecimento erudito.

Na França, no fim do século XIX, o termo intelligentsia foi preterido

[...] em favor do termo intelectual (intellectuel) ou, de forma mais precisa, intelectuais. A palavra no plural, designando o conjunto dos cultos, denota de forma mais precisa a existência de um protagonista político com identidade definida (Ibid., p. 70).

Porém, o autor coloca que foi na segunda metade do século XIX que o termo ganhou reconhecimento no âmbito francês, com o famoso caso Dreyfus ${ }^{6}$.

Embora o termo circulasse amplamente no ambiente cultural francês da segunda metade do século XIX, o marco simbólico da sua emergência foi o já 
célebre manifesto "J'accuse: lettre au président de la république", de Émile Zola, publicado no jornal L'Aurore, em dezembro de 1898. O texto tornou pública a posição de Zola sobre o affaire Dreyfus e produziu grande impacto no cenário político e cultural francês (Ibid., p. 70).

Assim como feito com o termo expert, buscou-se o significado do termo "intelectual" no Dictionnaire Universel, contenant generalement tous les mots françois, tant vieux que modernes, e les termes des sciences et des arts. A definição encontrada foi a seguinte:

INTELLECTUEL, elle. Adj. Qui appartienr à l'intellect, qui est dans l'entendement. Ainsi on dit, Faculté intellectuelle, vision intellectuelle, objet intellectuel, vertus intellectuelles, puissance intellectuelle.

INTELLECTUEL, elle, signifie aussi, Qui est purement spirituel, qui n'a point des corps. Les Anges sont substanstances purement intellectuelles. L'ame est une substance intellectuelle, um être intellectuel. Dans l'oraison passive toutes les puissances intellectuelles de l'ame sont liées \& suspendues. ${ }^{7}$ (Furetière, 1702b, p. 60).

Vê-se, com isso, a pluralidade semântica do vocábulo "intelectual" em diferentes regiões do globo no decorrer dos tempos. Mais uma vez, como diz a epígrafe, "não é fruto do acaso" (Hofstetter \& Schneuwly, 2017, p. 47).

Vieira (2008) ainda vai mais além em suas pesquisas: ele tenta fazer uma análise de como a palavra "intelectual" era utilizada por Karl Mannheim, Pierre Bourdieu e Antonio Gramsci. De acordo com Machado, Dorigão e Coelho (2016), os intelectuais

[...] ao serem tomados como objeto de estudo, espera-se que respondam questionamentos atuais, para demonstrar a permanência de determinadas questões ou soluções, de modo a tratá-los como "mitos" ou "heróis" que estavam fora do seu tempo por antecipar questões que serão consenso posteriormente. Assim, "desenraizados", são chamados para reafirmar uma ideia ou como autoridade portadora de argumentos indiscutíveis, não raro descolados do contexto social em que se formataram suas obras e ações (Machado, Dorigão \& Coelho, 2016, p. 176).

Ainda na tentativa de definir o vocábulo, os autores afirmam que "o intelectual é aquele que se ocupa do que não lhe diz respeito, é um indivíduo intrometido, curioso por natureza, que vai além de sua ocupação, devido ao seu espírito investigador e crítico" (Ibid., p. 180).

Além disso, estudiosos a respeito do tema na atualidade definem certas características que são comuns à definição de intelectuais tais como "o uso do conhecimento e erudição aliados à atuação social, propondo ações de transformação ou conservação da sociedade, seja inserido nos quadros de governo ou nos movimentos sociais" (Ibid., p. 182). O que se concluiu é que este intelectual não pode ser analisado fora de seu contexto, de seu momento histórico. Assim se posicionam os autores:

Não é possível o estudo de um "intelectual" que se volta para questões educacionais ou sociais isolando-o da vida material que dá sentido e significado para o papel que desempenha em determinado momento histórico. Isto é, não se pode desconsiderar aquilo que o autor diz dele mesmo ou o que se tem repetido pela historiografia educacional. Portanto, para alcançar resultados profícuos, faz-se necessário uma análise do conjunto da obra desse autor na intrincada rede de relações e fatos políticos, econômicos, culturais e sociais na qual ele forjou sua perspectiva teórica e política (Ibid., p. 185). 
Assim sendo, há que se preocupar, quando da classificação de um personagem como intelectual, não só com sua produção, mas principalmente em suas relações com o meio ao qual estava inserido.

Para este texto, o conceito de intelectual escolhido foi o de Vieira (2011). O autor elenca quatro aspectos que considera decisivos para a explicação histórica do intelectual como agente coletivo:

\begin{abstract}
a) sentimento de pertencimento ao estrato social que, ao longo dos séculos $X I X$ e $X X$, produziu a identidade social do intelectual; b) engajamento político propiciado pelo sentimento de missão ou de dever social; c) elaboração e veiculação do discurso que estabelece a relação entre educação e modernidade; d) assunção da centralidade do Estado como agente político para efetivação do projeto moderno de reforma social (Vieira, 2011, p. 29).
\end{abstract}

Este deve ser, portanto, o caminho metodológico a ser seguido quando da caracterização de um personagem como intelectual: a partir de sua trajetória pessoal e profissional e suas relações com seu meio, em seu momento histórico, deve-se analisar se estão presentes as quatro características acima apresentadas. Em caso positivo, o mesmo será um intelectual.

No entanto, não se tem experts e intelectuais como sinônimos. Adotam-se, assim, as palavras de Morais (2019):

Por certo que há similaridades, sobretudo com respeito aos processos e dinâmicas de evolução dos dois campos, o "campo intelectual" e o "campo ciências da educação", dinamizados por esses dois "sujeitos", os "intelectuais" e os "experts". Contudo, as referências aqui adotadas descrevem diferentes finalidades desses "sujeitos" (Morais, 2019, p. 10).

Como se vê, expert e intelectuais são duas categorias de análise consideradas como não-sinônimas, ou seja, não ditas como antônimas porque guardam relações entre si e, poder-se-ia dizer, até certas similaridades, mas diferem as características constitutivas de cada um bem como suas finalidades.

Como já apontado anteriormente, Conceição (2019) deixa claro que a diferença entre ambos é justamente o chamamento por parte do Estado para resolver certa demanda. Acredita-se, porém, que por ora é simples demais tomar por certa e acabada esta definição. Na caracterização de intelectual dada por Vieira (2011), o Estado também assume a posição central de agente político na efetivação do projeto moderno de reforma social e o intelectual, por definição, aceita e admite tal papel. Por vezes, certamente, devem também existir intelectuais "recrutados" pelo Estado.

Na mesma esteira, também há que se ter prudência na afirmação de que "todo expert é também um intelectual, mas nem todo intelectual é um expert" (Conceição, 2019, p. 48). Acredita-se que há critérios bem definidos para cada caso e que não se deve fazer generalizações. Mais do que classificar pessoas como experts ou intelectuais, o importante é identificar quais saberes produziram e fizeram circular.

Para ainda dar mais subsídios às pesquisas, pretende-se inserir no debate a figura dos polímatas, termo recentemente utilizado nas pesquisas do GHEMATBrasil, e verificar do que se trata e, da mesma maneira, traçar paralelos (ou não) com os experts e intelectuais. 


\section{O terceiro sintoma: os polímatas}

$\mathrm{Na}$ intenção de apresentar os desafios que o GHEMAT-Brasil enfrenta com as pesquisas em História da Educação Matemática em tempos de Humanidades Digitais $^{8}$, Valente (2020) aponta que, devido ao elevado número de documentos digitalizados, novas questões de abordagem metodológica surgiram e, com isso, novos desafios. Dentre alguns questionamentos levantados pelo autor, há que se mencionar um: "Como transformar a informação dispersa por entre milhares de documentos digitalizados na produção de um novo saber? Essa última interrogação nos remete ao título de recente obra do historiador Peter Burke" (Valente, 2020, p. 609).

A obra referida pelo autor é intitulada "O que é história do conhecimento?", de Peter Burke. No segundo capítulo de sua obra, Burke (2016) faz um apanhado de uma série de conceitos, tais como: disciplinas, estilos de pensamento, interdisciplinaridade, práticas, entre outros. Mas eis que um dos conceitos chama a atenção e, tal qual prescreve a epígrafe inicial, "é preciso atentar": intelectuais e polímatas. Como já visto, Morais (2019) tratou de relacionar intelectuais e experts. Mas intelectuais e polímatas, estes ainda não haviam sido discutidos.

$\mathrm{Na}$ obra, Burke (2016) não se estende no exercício de tentar relacionar ambos os conceitos: gasta menos do que duas páginas para discorrer sobre o tema. Inicia a sessão com a seguinte citação: "Uma história do conhecimento necessariamente se envolve com diferentes tipos de especialistas dentro e fora da universidade" (Burke, 2016, p. 51). Na tentativa de tratar sobre o termo intelectual, o autor refere-se ao sentido de escritor ou erudito "que se posiciona nas questões públicas" (Ibid., p. 51). Cita, como já dito anteriormente, o caso Dreyfus para ilustrar a situação do uso do termo.

Intrigante mencionar que, mesmo não constando no subtítulo, o autor também escreve a respeito do expert definindo-o como uma "espécie de sabedor", um "especialista" (Ibid., p. 52). Cita, apenas, que em meados do século XIX o termo fora utilizado no contexto médico, mas que logo passara a ser utilizado de forma mais abrangente.

Mas é logo em seguida que o autor apresenta: "Uma espécie bastante distinta é a do erudito familiarizado com várias disciplinas diferentes, o polímata ou "generalista"” (Burke, 2016, p. 52). Na primeira tentativa de definição, não há elementos suficientes que permita pesquisadores classificarem determinados sujeitos como polímatas.

De acordo com o autor, o termo começou a ser utilizado no século XVII mas, no século XVIII, com a crescente especialização do conhecimento, seu uso beirou à extinção.

Burke (2016) escreve que há dois tipos de polímatas: o passivo, ou seja, aquele que não oferece nenhuma contribuição significativa ao conhecimento em si; e o serial, que tem uma formação numa determinada área específica, mas depois migra para outras. Este último, segundo o autor, pode "levar ideias ou métodos utilizados em um campo e empregá-los em outro" (Burke, 2016, p. 53). O termo quase desconhecido é, no mínimo, intrigante. Faz-se, portanto, uma tentativa de historicização do vocábulo, tal qual os outros dois. 
Ao fazer a pergunta "Quando declinou o tipo de intelectual a que chamamos de "polímata"?", Burke (2011) já estaria definindo o polímata como uma categoria de intelectual? Seriam, portanto, sinônimos? Poder-se-ia, assim, afirmar que todo polímata é um intelectual, mas nem todo intelectual é um polímata? Se assim o fosse, há intelectuais que não são polímatas! Então, como podem ser classificados os intelectuais? Desenrolar essas respostas certamente não seria tarefa muito simples. De acordo com o autor, "a ideia do polímata surgiu como uma reação à especialização crescente, da mesma maneira que no século $X X$ a ideia de interdisciplinaridade apareceu no contexto de uma era de disciplinas (Burke, 2011, p. 1).

Para o autor, quando se tem alterações vocabulares é porque mudanças culturais significativas acontecem. E é isso que ele tenta explicar nas linhas de seu trabalho.

De acordo com Burke, o termo polímata passou a se utilizado no século XVII, bem como o termo poli-historiador (polyhistor). Ambos os termos passaram a ser utilizados em latim, francês, inglês e alemão. Em francês, por exemplo, o termo empregado era polymathie.

Johann von Wower publicou o primeiro tratado sobre polimatia na Europa Central, em 1603, intitulado De polymathia. Já em 1687, Daniel Morhof, um bibliotecário alemão, publicou a primeira edição do livro Polyhistor. Estes tratados chamaram a atenção para um problema emergente à época: a crise do conhecimento (Burke, 2011).

Ainda de acordo com Burke (2011), o século XVII era chamado como a "era da ansiedade", o momento em que a polimatia se tornou um objeto de debate. "Não pode ser um bom pensador aquele que não for um pensador universal" eram os escritos constantes no Of Industry, escrito pelo Diretor da Universidade de Trinity, Cambridge, Isaac Barrow. Ao que se desenha, devia-se ter o conhecimento do todo ou de muitas coisas.

Para Burke (2011), Gottfried Wilhelm Leibniz foi o polímata mais famoso do século XVII:

\begin{abstract}
Em seus dias, Leibniz foi também conhecido por sua máquina de calcular e por seu trabalho sobre a história medieval alemã, sem mencionar seus interesses por direito, teologia, sinologia, geologia, biblioteconomia e linguística (ele era interessado na história dos dialetos e estava consciente das semelhanças estruturais entre o húngaro e o finlandês). Não é de surpreender, portanto, que Morhof afirmasse no seu tratado que a polimatia era ainda possível de existir (Burke, 2011, p. 3).
\end{abstract}

A ascensão do termo foi, de fato, no século XVII. Nos seguintes, iniciou-se o declínio do uso do termo, haja vista a fragmentação do conhecimento em diversas áreas ou campos. Os estudiosos foram perdendo a "capacidade de ver o todo" (Ibid., p. 3).

Nos séculos XVIII e XIX, o termo polímata foi utilizado para "referir-se a estudiosos que inovaram em mais de um campo, ou mesmo para uma pessoa envolvida em trabalhos interdisciplinares" (Ibid., p. 3). Porém, apesar de quase desaparecerem, ainda restaram alguns com certo prestígio:

Veja também o caso de Thomas Young do Emmanuel College, um dos três "últimos
homens que sabiam tudo". Young foi treinado como médico e fez pesquisas em
medicina, mas também publicou importantes artigos sobre o cálculo do seguro de vida
ou sobre a física da luz e do som. Ele colaborou para a decodificação dos hieróglifos

History of Education in Latin America - HistELA, v. 3, e23450, 2020, p. 11 de 17 
egípcios (ainda que ele fosse menos conhecido do que Jean-François Champollion) e contribuiu com não menos de 63 artigos para o Suplemento da sexta edição da Enciclopédia Britânica sobre um amplo leque de assuntos, de "línguas" a "marés". O "Fenômeno Young", como os seus contemporâneos o chamavam, foi um pensador excepcional (Ibid., p. 3-4).

A ideia que fica implícita é a de que o "homem que sabia tudo", ou seja, aquele que detinha conhecimento em várias áreas era tido com um "fenômeno", ou seja, um polímata.

Como se trata do século em que a obra de Furetière (1702b) está inserida, foi também realizada, à mesma maneira que os dois outros termos, a busca pelo termo polymathie. Não foram localizados, naquela obra, verbetes que se relacionassem a este. Simplesmente não constava no dicionário da época.

Avançando um pouco mais no tempo, consultando uma obra do século XIX (Dictionnaire de l'Académie Français) ${ }^{9}$, os termos polymathie e polymathique foram localizados. A sétima edição datada de 1878 traz a seguinte definição:

POLYMATHIE. s.f. Instruction multiple, varieé, étendue.

POLYMATHIQUE. adj. des deux genres. Qui a rapport à la polymathie. École polymathique, École où l'on enseigne beaucoup de sciences ${ }^{10}$ (Institut de France, 1878, p. 456).

No início do século $X X$, também é possível perceber a permanência do vocábulo no Dicionário. A oitava edição datada de 1935 pela Librairie Hachette traz, exatamente, a mesma definição, sem nenhuma alteração na descrição.

Porém, importante destacar que o Dicionário da Academia Francesa se encontra, atualmente, em sua $9^{a}$ edição. Se a consulta for realizada, é possível perceber que ambos os termos não mais constam no respectivo dicionário, ou seja, pode-se inferir que o termo caiu em desuso, motivo pelo qual foi retirado do dicionário na segunda metade do século XX e início do século XXI.

Em se tratando do século XX, Burke (2011) ainda elenca dois exemplos que dizem respeito à Matemática e, também, à História da Educação Matemática:

Na França, pensa-se em Henri Poincaré, cujas conhecidas contribuições à matemática
foram flanqueadas por estudos de física, de longitude, de minas e de filosofia da ciência;
ou, mais recentemente, no jesuíta Michel de Certeau, que gostava de se apresentar
como historiador, mas era também versado em filosofia, teologia e psicanálise (na
escola de Jacques Lacan), dando contribuições à sociologia e à antropologia (BURKE,
2011, p. 6).

Poincaré tem uma série de contribuições para a Matemática e surge como polímata, uma classificação que poderá se desdobrar em pesquisas futuras. Certeau tem norteado pesquisas do GHEMAT-Brasil a partir de sua "operação historiográfica", conceitos que mobilizam estudos históricos. Classificá-lo como polímata pode, certamente, também gerar uma série de novos trabalhos.

Soares Júnior (2016), em sua Dissertação de Mestrado, classifica o próprio Peter Burke como um polímata. Para este autor, a definição de polímata é bastante simples: "Polímata é o indivíduo que estuda ou que conhece muitas ciências" (Soares Júnior, 2016, p. 41). Além disso, incrementa sua definição de polímata ao afirmar que é "um intelectual que também é um sábio, com erudição que poucos possuem hoje" (Ibid., p. 43). Apesar de relacionar os termos polímata e intelectual, 
carece de elementos que auxiliem na classificação e no aprofundamento da definição.

Burke (2011) defende a existência de "especialistas em conhecimento geral" (Burke, 2011, p. 6) e ainda suplica:

\begin{abstract}
Nosso problema é que, numa era de fragmentação, nós precisamos da contribuição do polímata para a organização do conhecimento, e muito mais do que antes, mesmo porque a nossa sociedade oferece cada vez menos espaço para essa espécie em extinção no quadro da organização social do conhecimento, cada vez mais dominada por equipes de pesquisa e gerentes intelectuais do que por solitários estudiosos fora de moda. O que se pode fazer? (Burke, 2011, p. 6).
\end{abstract}

A pergunta de Burke não parece ter resposta simples e imediata. Também não se pretende construir aqui um dicionário com cada termo e sua classificação como substantivo, adjetivo, ou qualquer outra classe gramatical. Tampouco se pretende engessar as definições dos termos. O que se propõe é dar luz aos termos utilizados e verificar que possibilidade de pesquisa isso pode gerar.

\title{
Não é fruto do acaso, mas o sintoma de uma realidade à qual é preciso atentar
}

A escrita deste trabalho se inicia e se encerra com os dizeres de Hofstetter e Schneuwly (2017), que se denominou de epígrafe durante a escrita. Não, o uso da mesma palavra em muitas línguas não é fruto do acaso. Tem-se intencionalidade em sua inserção no cotidiano. Tem sentido impregnado em sua utilização.

$\mathrm{O}$ que se tentou mostrar neste trabalho foi justamente o uso das palavras expert, intelectual e polímata em diferentes línguas, em diversos países, em diferentes contextos, em momentos históricos distintos. Nada ao acaso. Tudo de forma proposital.

Se seu uso era um sintoma de uma realidade à qual era preciso atentar, buscou-se exatamente dar esta atenção: cada vocábulo se tornou um sintoma de uma realidade, na expectativa de desvendar o que de significado tinha-se por detrás de cada "sintoma".

As pesquisas realizadas pelo GHEMAT-Brasil têm mobilizado categorias com o intuito de discutir aspectos do ensino e da formação de professores que ensinam matemática, com vistas à objetivação e institucionalização de saberes profissionais. Estas relações têm a intenção de auxiliar neste debate trazido à tona na cena educacional.

Os experts têm definição própria relacionado a uma personagem que se destaca no meio educacional por meio de sua expertise, atendendo a um chamado do Estado para resolver tecnicamente uma questão, que pode resultar em reformas educacionais, mas que produzam um determinado saber, que circulará, objetivarse-á e institucionalizar-se-á.

Já os intelectuais, a partir do referencial teórico adotado, têm características constituintes próprias bem definidas. A personagem estudada dará subsídios para

History of Education in Latin America - HistELA, v. 3, e23450, 2020, p. 13 de 17 
que sua trajetória pessoal e profissional, seu sentimento de pertença, seu espírito de modernidade e sua aceitação do Estado como propulsor de mudanças sociais possam assim classificá-lo como tal.

Por conseguinte, os polímatas representam, dentre os três, a classe com maior perigo de extinção. É comparado a um estudioso, sábio, que detêm conhecimento de várias áreas, um generalista, um conhecedor universal que pode (mas nem sempre) também ser classificado como intelectual e/ou expert. Depende daquilo a que se propôs a fazer e se o fez com excelência.

A atenção requerida na epígrafe foi dada aos termos propostos. São sinônimos? Não! Definitivamente. Tampouco são antônimos. Há aproximações e distanciamentos. Mas só a análise do material empírico conseguirá subsidiar essa classificação. Os elementos necessários estão aqui expostos. Porém, ressalta-se que o foco deve estar não na classificação, mas sim, naquilo que foi produzido por cada um do que se chamou aqui de sintoma. Cada sintoma de uma realidade produz conhecimento. E é a esse a quem, agora, deve-se atentar.

\section{Referencias}

Bertini, L. de F.; Morais, R. dos S. \& Valente, W. R. (2017). A matemática a ensinar e a matemática para ensinar: novos estudos sobre a formação de professores. São Paulo: Editora Livraria da Física.

Burke, P. (2011). O polímata: a história cultural e social de um tipo intelectual. Tradução de Ezequiel Theodoro da Silva. Leitura: Teoria e Prática, 29(56), 4-10.

Burke, P. (2016). O que é história do conhecimento? Tradução Cláudia Freire (1 ed.). São Paulo: Editora UNESP.

Conceição, G. L. da. (2019). Experts em educação: circulação e sistematização de saberes geométricos para a formação de professores (Rio de Janeiro, final do século (Tese de Doutorado). Retirado de <https://repositorio.ufsc.br/handle/123456789/201374>.

Furetière, A. (1702a). Dictionnaire universel, contenant généralement tous les mots françois tant vieux que modernes, \& les termes des sciences et des arts. Tome 1. $2 e$ édition revue, corrigée et augmentée par $M$. Basnage de Bauval. Bibliotheque Nacional de France : A La Haye et à Rotterdam.

Furetière, A. (1702b). Dictionnaire universel, contenant généralement tous les mots françois tant vieux que modernes, \& les termes des sciences et des arts. Tome 2. 2 e édition revue, corrigée et augmentée par M. Basnage de Bauval. Bibliotheque Nacional de France : A La Haye et à Rotterdam.

Hofstetter, R. \& Schneuwly, B. (2014). Disciplinarisation et disciplination consubstantiellement liées. Deux exemples prototypiques sous la loupe: les 
sciences de l'éducation et des didactiques des disciplines. In Balz Engler (Hrsg/Éd.), Disziplin-Discipline pp. 27-46. Fribourg: Academic Press.

Hofstetter, R. \& Schneuwly, B. (2017). Disciplinarização e disciplinação: as ciências da educação e as didáticas das disciplinas sob análise. In R. Hofstetter \& W. R. Valente (Orgs.), Saberes em (trans)formação: tema central da formação de professores (1. ed.). São Paulo: Editora Livraria da Física.

Hofstetter, R., Schneuwly, B. \& Freymond, M. de. (2017). "Penetrar na verdade da escola para ter elementos concretos de sua avalição" - A irresistível institucionalização do expert em educação (século XIX e XX). In R. Hofstetter \& W. R. Valente (Orgs.), Saberes em (trans)formação: tema central da formação de professores (1. ed.). São Paulo: Editora Livraria da Física.

Institut de France. (1878). Dictionnaire de l'Académie Français. Septième Édition. Tome Second I-Z. Paris: Librairie de Firmin-Didot et $\mathrm{C}^{\mathrm{ie}}$, Retirado de <https://gallica.bnf.fr/ark:/12148/bpt6k1280427w/f9.item>.

Machado, M. C. G., Dorigão, A. M. \& Coelho, G. F. (2016). As pesquisas com intelectuais em História da Educação: um campo profícuo. Revista HISTEDBR Online, 67, 175-188, Retirado de $<$ https://periodicos.sbu.unicamp.br/ojs/index.php/histedbr/article/view/8645233/132 94>.

Morais, R. dos S. (2018). Experts. In W. R. Valente (Org.). Cadernos de Trabalho II, v. 6. São Paulo: Editora Livraria da Física.

Morais, R. dos S. (2019). “Intelectual? Não”, expert. Acta Scientiae, 21 (n. especial), 3-12, Retirado de <http://www.periodicos.ulbra.br/index.php/acta/article/view/5169>.

Soares Júnior, J. R. (2016). Peter Burke um historiador da cultura e da sociedade: as muitas faces de um intelectual polímata. (Dissertação de Mestrado). Retirado de <https://tede2.pucsp.br/handle/handle/19440>.

Tochon, F. V. (2004). Autour des mots - le nouveau visage de lénseignant expert. In F. V. Tochon (rédacteur em chef invité). Recherche et Formation - pour les professions de l'education. La construction de L'Expert (Revue Éditée par L'INPP) pp. 89-104. Paris/Lyon. Retirado de <http://ife.ens-lyon.fr/publications/editionelectronique/recherche-et-formation/RR047-08.pdf>.

Valente, W. R. (2020). O GHEMAT-Brasil e a pesquisa coletiva em história da educação matemática. Historia y Memoria de la Educación, 11, 595-613. Retirado de <http://revistas.uned.es/index.php/HMe/article/view/24266>.

Vieira, C. E. (2011). Erasmo Pilotto: identidade, engajamento político e crenças dos intelectuais vinculados ao campo educacional brasileiro. In J. L. Leite \& C. Alves (Org.). Intelectuais e história da educação no Brasil: poder, cultura e políticas. Vitória: EDUFES. 
Vieira, C. E. (2015). Intelectuais e Educação. Pensar A Educação em Revista, 1(1), 3-21, Retirado de <http://pensaraeducacaoemrevista.com.br/wpcontent/uploads/sites/4/2017/04/vol_1_no_1_Carlos_Eduardo_Vieira.pdf>.

Vieira, C. E. (2008). Intelligentsia e intelectuais: sentidos, conceitos e possibilidades para a história intelectual. Revista Brasileira de História da Educação, 8(1), 63-85.

\title{
Notas
}

\author{
${ }^{1}$ https://www.ghemat-brasil.com/ \\ ${ }^{2}$ A definição de proprietaire-foncier é a pessoa que possui em sua propriedade bens imóveis. Assim, \\ a expressão pode ser traduzida como "Especialistas e código do proprietário" (tradução livre dos \\ autores). \\ ${ }^{3}$ ESPECIALISTA, adj. Quem é hábil em sua arte. O especialista Marechal. Este cirurgião é muito \\ especialista em sua arte.
}

ESPECIALISTA às vezes é substantivo e significa um homem inteligente, familiarizado com alguma coisa, a quem alguém nomeia para visitar e relatar sobre ela. Os reparos serão visitados por especialistas e pessoas para este conhecedor. A gente paga os frutos da redenção de um alívio, de acordo com os especialistas. São necessários dois especialistas para a validade de um relatório: se uma das partes se recusar a concordar com um especialista, o juiz nomeia oficiosamente. Por decreto do Conselho em 1690, o rei criou um certo número de especialistas jurando para cada cidade do Reino e para a de Paris: isto é: Arquitetos, empreiteiros, pedreiros e carpinteiros, que podem ser nomeados oficiosamente para serem árbitros de disputas entre os burgueses. Esses especialistas em suas descidas e visitas devem ser acompanhados por um balconista de edifícios, disse sobre a redação, para escrever a ata de seu relatório e, quando não concordam, um nomeia um terceiro para decidir a contestação (tradução livre dos autores).

${ }^{4}$ O termo "disciplinarização" aqui é entendido como "o processo complexo de formação do sistema disciplinar e de seus componentes, as disciplinas" (Hofstetter \& Schneuwly, 2017, p. 24).

${ }_{5}$ Durante muito tempo, e ainda em alguns setores, considerou-se que especialistas em ensino estavam fora da profissão. Por exemplo, afirma que o Inspetor Nacional de Educação é um especialista de primeiro nível (1): através de suas atividades educacionais, garante a implementação da política ministerial. Ele inspeciona os professores e avalia seu trabalho em equipe, participa de seu recrutamento e treinamento. As pessoas de treinamento de professores também se beneficiam do reconhecimento como especialistas (tradução livre dos autores).

${ }^{6}$ Sobre o affaire Dreyfus ver Los intelectuales en el siglo XIX (2000) e Histoire sociale de la France au XIX siecle (1998), de Cristopher Charle. "Esse acontecimento tornou-se uma referência para a história política francesa no cenário da Terceira República e produziu uma profunda comoção e divisão do campo cultural e político do país. O episódio demarcou a ação pública de artistas, cientistas e escritores contra o Estado, devido à quebra de normas jurídicas no processo que este movia contra o capitão Alfred Dreyfus. Em 1894, esse militar foi acusado de espionagem em favor da Alemanha e, posteriormente, encarcerado na Ilha do Diabo, na costa da Guiana Francesa. O conflito, além de gerar o recrudescimento do discurso nacionalista entre aqueles que se opunham à reabertura do processo na justiça militar francesa, fomentou o sentimento antissemita, uma vez que Dreyfus era de origem judaica. Émile Zola, Octave Mirbeau, Anatole France, Marcel Proust, Henri Poincaré, Émile Durkheim, entre outros, manifestaram-se em favor do militar, reivindicando, através de jornais e revistas, que o tribunal de justiça analisasse o caso com base em normas jurídicas de valor universal e não em função da lógica conjuntural dos interesses de Estado. Esse acontecimento, que mobilizou o debate político francês entre o final do século $X I X$ e o início do $X X$, foi exaustivamente discutido na grande imprensa, nos jornais ligados aos partidos políticos e nas revistas de cultura" (Vieira, 2015, p. 4-5).

7 INTELECTUAL, adj. Quem pertence ao intelecto, quem está no entendimento. Assim dizemos: faculdade intelectual, visão intelectual, objeto intelectual, virtudes intelectuais, poder intelectual.

INTELECTUAL também significa: Quem é puramente espiritual, quem não tem corpo. Anjos são substâncias puramente intelectuais. A alma é uma substância intelectual, um ser intelectual. $\mathrm{Na}$ oração passiva, todos os poderes intelectuais da alma estão ligados e suspensos (tradução livre dos autores).

8 "Expressão que designa uma nova era das pesquisas nas ciências humanas ancorada no uso de dados alocados em grandes repositórios de conteúdos digitais" (Valente, 2020, p. 607).

${ }_{9}$ Disponível em: https://www.dictionnaire-academie.fr/ 
10 POLIMATIA. s.f. Instrução múltipla, variada e extensa.

POLIMÁTICO. adj. de ambos os gêneros. O que tem a ver com polímata. Escola Polimática, escola onde muitas ciências são ensinadas (tradução livre dos autores). 